\title{
Non-Hodgkin's lymphoma in systemic lupus erythematosus
}

\author{
S Bernatsky, R Ramsey-Goldman, R Rajan, J-F Boivin, L Joseph, S Lachance, D Cournoyer, \\ A Zoma, S Manzi, E Ginzler, M Urowitz, D' Gladman, P R Fortin, S Edworthy, S Barr, C Gordon, \\ S-C Bae, J Sibley, K Steinsson, O Nived, G Sturfelt, Y St Pierre, A Clarke
}

Ann Rheum Dis 2005;64:1507-1509. doi: 10.1136/ard.2004.034504

\begin{abstract}
Background: Recent evidence supports an association between systemic lupus erythematosus (SLE) and nonHodgkin's lymphoma (NHL).

Objectives: To describe demographic factors, subtypes, and survival of patients with SLE who develop NHL.

Methods: A multi-site cohort of 9547 subjects with definite SLE was assembled. Subjects at each centre were linked to regional tumour registries to determine cancer cases occurring after SLE diagnosis. For the NHL cases ascertained, descriptive statistics were calculated, and NHL subtype frequency and median survival time of patients determined. Results: 42 cases of NHL occurred in the patients with SLE during the 76948 patient-years of observation. The median age of patients at $\mathrm{NHL}$ diagnosis was 57 years. Thirty six $(86 \%)$ of the 42 patients developing NHL were women, reflecting the female predominance of the cohort. In the patients, aggressive histological subtypes appeared to predominate, with the most commonly identified $\mathrm{NHL}$ subtype being diffuse large B cell 111 out of 21 cases for which histological subtype was available). Twenty two of the patients had died a median of 1.2 years after lymphoma diagnosis.

Conclusions: These data suggest aggressive disease in patients with SLE who develop NHL. Continuing work should provide further insight into the patterns of presentation, prognosis, and aetiology of NHL in SLE.
\end{abstract}

I the past three decades, data has accumulated about an increased risk of lymphoma, particularly non-Hodgkin's lymphoma (NHL), in systemic lupus erythematosus (SLE). ${ }^{1-3}$ The reasons for this increased risk are unknown. In the general population, NHL risk is determined by various factors, including age, sex, and race, among others. ${ }^{4-6}$ In general, more aggressive lymphoma types can arise in immunosuppressed states. ${ }^{7}$ Relatively aggressive subtypes appear to dominate lymphomas seen in rheumatoid arthritis, which, like SLE, is associated with an increased risk of NHL. ${ }^{8}$ In contrast, in primary Sjögren's syndrome (also associated with NHL) the commonest lesions are low grade (indolent), marginal zone lymphomas related to mucosa associated lymphoid tissue (MALT). ${ }^{9}$

Little is known about the frequency of NHL subtypes in SLE. This is unfortunate, because determining subtype predominance in SLE might be an important step in exploring pathogenic mechanisms for the association of NHL and SLE. This has not been possible to date because of the small absolute number of NHL cases in single centre studies.

We recently completed a multi-site international cohort study that calculated standardised incidence ratios for cancer in SLE in comparison with the general population. The standardised incidence ratio for NHL was 3.6 (95\% confidence interval (CI) 2.6 to 4.9), ${ }^{1}$ consistent with other studies, although our estimates were more precise. The objectives of the current paper are to report the subtype distribution of NHL in this SLE cohort, and to describe pertinent demographic factors (for example, age, sex, race) in these subjects. We also provide some preliminary work on the stage and survival of the patients with SLE in whom an NHL occurred.

\section{MATERIALS AND METHODS}

We assembled a multi-site international cohort study involving 23 clinical centres in Canada, America, the UK (England and Scotland), Sweden, Iceland, and Korea. ${ }^{1}$ All patients with definite SLE according to American College of Rheumatology or clinical criteria were eligible.

Data were available on patient birth date and sex, dates of SLE diagnosis and cohort entry, and vital status. Cases of NHL occurring after SLE diagnosis were ascertained by regional cancer registry linkage. For the observation interval, we subtracted the later of two entry dates (beginning of cancer registry observation interval or first visit to the respective SLE clinic) from the earlier of two exit dates (end date of tumour registry data or death). The calendar time spanned 1958-2000.

We calculated descriptive statistics for demographics (age, sex, race) for all patients with NHL occurring within the observation interval, and the SLE duration at the time of NHL diagnosis. We ascertained the frequency of histological subtypes and tumour stage, where known. As well as determining the median and mean survival times after NHL diagnosis, we calculated the Kaplan-Meier estimate for the 5 year survival probability.

\section{RESULTS}

In total, 9547 patients with SLE were observed for a total of 76948 patient-years. ${ }^{1}$ Forty two cases of NHL occurred during the observation interval.

The mean age at the time of NHL diagnosis in our sample was 55.3 years (SD 15.1, median 57, interquartile range 18). Among the 42 NHL cases, 36 (86\%) patients were women. The majority of subjects who developed NHL were white $(n=20,48 \%)$; the remainder were black $(n=5,12 \%)$, other (one native North American, one Asian) or unknown ( $\mathrm{n}=15$, $36 \%)$. Average SLE duration at the time of NHL diagnosis was 6.7 years (SD 5.8, median 4.0, interquartile range 8).

For 21 of the NHL cases found on tumour registry linkage, the subtype was not specified. The most common NHL type among the remaining 21 cases was diffuse large B cell $(\mathrm{n}=11,52 \%$ of the cases of known subtype), with the remainder being small lymphocytic $(n=4,19 \%)$, follicular

Abbreviations: $\mathrm{Cl}$, confidence interval; MALT, mucosa associated lymphoid tissue; NHL, non-Hodgkin's lymphoma; SLE, systemic lupus erythematosus 
( $\mathrm{n}=3,14 \%)$, and one each of Burkitt's, peripheral T cell, and MALT lymphoma.

In only $14 / 42(33 \%)$ cases of NHL was staging information available. Of these 14 , five (36\%) were localised disease, and the remainder were advanced (two regionally spread, the others widespread) stage.

Twenty two $(52 \%)$ of the 42 cases had died a median of 1.2 years after lymphoma diagnosis. The remaining subjects had survived for a median of 2.1 years. Of the 21 cases where information on subtype was incomplete, nine subjects $(43 \%$ of these 21 cases) had died after a median survival of 0.5 years (mean (SD) 2.5 (2.9)). Of the 22 patients with SLE and NHL who had died, information on specific cause of death was available in 10 cases, the primary cause of death being malignancy in all but one of these (in whom congestive heart failure was the cause of death). After diagnosis of NHL, the Kaplan-Meier estimate for the probability of survival to 5 years was $46.8 \%$ ( $95 \%$ CI 19.6 to 73.9 ).

\section{DISCUSSION}

In general, NHL is more common in $\mathrm{men}^{7}$; indeed the percentage of men among our subjects who developed NHL ( $14 \%)$ was slightly higher than the percentage of men in the entire cohort $(10 \%) .^{1}$ NHL incidence is also highest among white subjects ${ }^{7}$; this was possibly reflected in our sample because the proportion of white subjects among the NHL cases (74\% of all cases where race was known) was slightly higher than the proportion of white subjects in the entire cohort (just under $70 \%$ ). ${ }^{10}$

"Anticipation" is a term describing the phenomenon whereby subjects who have strong genetic determinants of cancer present for investigation at an earlier age than the norm. ${ }^{11}$ For the general population, the median age at NHL diagnosis is $60-65$ years. ${ }^{7}$ The slightly lower median age at time of cancer diagnosis for the patients with NHL in our cohort may be due to an overall younger age distribution of subjects with SLE than in the general population. Thus, one cannot necessarily interpret our findings as suggestive of a genetic basis for an association between NHL and SLE.

NHL can be divided into two general prognostic groups: indolent lymphomas and more aggressive (intermediate or high grade) lymphomas. ${ }^{7}$ Of the 21 NHL of known type occurring during the observation interval, only nine were probably indolent, with the remaining being more aggressive (diffuse large B cell and Burkitt's) lymphoma.

The diffuse large B cell subtype makes up about $30 \%$ of all NHL lymphomas in the general population, ${ }^{7}$ but represented more than half of the NHL lymphomas of known cell type in our sample (a difference of $22.4 \%$, 95\% CI 2.2 to $41.8 \%$ ). Information about tumour subtype was inadequate for many of the cases. However, the median survival time of patients with NHL of unknown subtype was 2.1 years, which is in keeping with more aggressive kinds of NHL. However, because diffuse large B cell lymphomas may arise from other lesions, ${ }^{12}$ it is possible that some of the diffuse large B cell lymphomas seen in our sample arose from previously unrecognised more indolent disease.

Only one of the patients with SLE observed developed a MALT lymphoma during the study interval. This is of interest, because some speculate that the increased NHL risk in SLE might relate to overlap with Sjögren's syndrome. Given our findings, it appears unlikely that identical pathological processes are occurring in the cases of cancer that develop in patients with Sjögren's syndrome and SLE.

The genetic abnormalities underlying the association between SLE and NHL are unknown. An important feature of NHL is the presence of chromosomal abnormalities (table 1), such as translocations in which an oncogene is juxtaposed next to a gene important for immune cell function. ${ }^{7}$ These chromosomal abnormalities may represent common pathways linking SLE and lymphoproliferative malignancies. Specifically, the same oncogenic factors implicated in NHL may be important in SLE pathogenesis, where uncontrolled lymphocyte proliferation also occurs.

We are unable to comment about specific translocations in the NHL cases that arose in our subjects. For the present, a reasonable hypothesis is that uncontrolled lymphocyte activity in active SLE leads to chromosomal translocations that allow malignant transformation. ${ }^{13}$ However, the effect of immunosuppressive agents and viral exposures (such as the Epstein-Barr virus are also of interest. These factors are currently under study.

The likelihood of extrinsic exposures (such as drugs) would presumably increase with SLE duration; intrinsic immunopathology might also vary with time. Given this, it would be interesting to know whether the histological subtypes differ for those patients who developed NHL early (versus later) in the course of SLE. Unfortunately, the relatively small number of NHL cases hampered our examination of this issue. We note that of the 21 cases where NHL subtype was known, two had occurred within a year of the SLE diagnosis; one of these was a diffuse large B cell lymphoma. In the remaining 19 cases where NHL subtype was known (all occurring more than a year after SLE diagnosis), 10 (53\%) were diffuse large B cell.

In general, with current treatment, median survival for NHL in the general population exceeds 5 years ${ }^{14}$; this rate has been relatively stable for the past three decades, which is when the NHL cases in our cohort occurred. Median survival for indolent NHL types is estimated at $8-10$ years. Twenty two of our 42 cases had died after a median of 1.2 years. The remaining subjects had survived to a median of 2.1 years.

Table 1 Reported chromosomal abnormalities seen in specific subtypes of NHL

\begin{tabular}{|c|c|c|c|c|}
\hline Translocation & $\begin{array}{l}\text { Associated } \\
\text { histology }\end{array}$ & $\begin{array}{l}\text { Oncogene } \\
\text { affected }\end{array}$ & $\begin{array}{l}\text { Molecular } \\
\text { events }\end{array}$ & Comments \\
\hline $\begin{array}{l}t(3 ; 16) \\
(q 27 ; p 11)\end{array}$ & $\begin{array}{l}\text { Diffuse large } B \\
\text { cell (DLBC) }\end{array}$ & $b c l-6$ & $\begin{array}{l}\text { Lymphocyte } \\
\text { proliferation }\end{array}$ & $\begin{array}{l}16-35 \% \text { of DLBC and } \leqslant 13 \% \text { of follicular NHL } \\
\text { have bcl-6 translocation } 15 \% \text { of DLBC have } \\
\text { bcl- } 1 \text { translocation Mutations of the p53 } \\
\text { suppressor gene may also be seen in DLBC } \\
\text { (especially those that transformed from FL) }\end{array}$ \\
\hline $\begin{array}{l}t(14 ; 18) \\
(q 32 ; q 21)\end{array}$ & Follicular (FL) & $b c l-2$ & $\begin{array}{l}\text { Apoptosis } \\
\text { inhibition }\end{array}$ & $\begin{array}{l}80-90 \% \text { of } \mathrm{FL} \text {, and } 6-30 \% \text { of DLBC have } b c l-2 \\
\text { translocation (These DLBC may represent } \\
\text { transformation from } \mathrm{FL} \text { ) }\end{array}$ \\
\hline $\begin{array}{l}t(8: 14) \\
(q 24: q 32)\end{array}$ & Burkitt's & $c-m y c$ & $\begin{array}{l}\text { Lymphocyte } \\
\text { proliferation }\end{array}$ & $\begin{array}{l}\text { Translocation of } t(8: 14) \text { and others involving } c^{-} \\
\text {myc present to a lesser extent in DLBC }(\sim 10 \%)\end{array}$ \\
\hline $\begin{array}{l}t(1 ; 14) \\
(p 22 ; q 32)\end{array}$ & $\begin{array}{l}\text { Marginal zone } \\
\text { (MALT) }\end{array}$ & bcl-10 & $\begin{array}{l}\text { Apoptosis } \\
\text { inhibition }\end{array}$ & $\begin{array}{l}\text { Another translocation, } t(15 ; 16)(p 21, q 21) \text { in } \\
\sim 25 \% \text { of MALT }\end{array}$ \\
\hline
\end{tabular}


This suggests that patients with SLE who develop NHL do not fare as well as most patients with NHL. This is particularly interesting given that the majority of the patients with NHL in our sample were young, white women, which are traditionally indicators of good prognosis.

We do not have information about the cancer treatment given to the patients with SLE who developed NHL, or data about their response and relapse rates after treatment. However, we are embarking upon a review of the pathology and clinical factors (including prognostic factors at presentation (particularly stage), treatment, response, and relapse) of the NHL cases that arose in our SLE sample.

If more aggressive tumour types or late stage of presentation are more common in SLE, these might lead to a lower than expected survival. Also, some therapeutic measures may be inappropriately withheld from patients with SLE who develop cancer. ${ }^{15}$ Other possible reasons for our observed data include decreased survival related to SLE comorbidity.

In summary, we have completed the most comprehensive assessment to date of NHL cases within a large SLE cohort. These data suggest more aggressive disease in patients with SLE who develop NHL compared with the general population. Continuing work should provide much needed insight into the aetiology of NHL in SLE.

\section{ACKNOWLEDGEMENTS}

We wish to acknowledge the following grant support:

S Bernatsky: Canadian Institutes of Health Research (CIHR)/Lupus Canada Fellowship; Canadian Arthritis Network Fellowship; Lupus Manitoba Science Grant. R Ramsey-Goldman: Arthritis Foundation, Clinical Science Grant, Arthritis Foundation Greater Chicago National Institutes of Health (NIH) No AR 02138, No AR 48098, Lupus Foundation of Illinois Chapter Grant. R Rajan: Fonds de la recherche en sante du Quebec (FRSQ) Clinician Scholar. L Joseph: senior CIHR investigator. PR Fortin: Dr Fortin is an investigator of the Arthritis Society/Institute of Musculoskeletal Health and Arthritis (TAS/IMHA) of the Canadian Institute of Health Research (CIHR), the director of clinical research of the Arthritis Centre of Excellence, University of Toronto and is partially funded by the Lupus Clinical Trial Consortium (LCTC). O Nived, G Sturfelt: Swedish Medical Research Council No 13489. A Clarke: National Cancer Institute of Canada (NCIC) No 013135; the Arthritis Society No 99105; CIHR No 10005; Singer Family Fund for Lupus Research; CIHR Investigator Award.

Angela Allen and Natalie Gonzalez were research co-coordinators responsible for all American sites.

We wish to thank the following physicians for their considerable assistance in providing patient access and the collection of data: Simon Bowman, Linda Lee, Moon-Ho Leung.

We would like to acknowledge the following tumour registries, which performed the linkage studies and provided population data: the Quebec Tumour Registry, Cancer Care Ontario, Saskatoon Cancer Centre, Alberta Tumour Registry, Illinois State Cancer Registry, New York State Tumor Registry, Pennsylvania Cancer Incidence Registry, British West Midlands Cancer Registry, the Swedish Cancer Registry, the Icelandic Tumour Registry, the Korean Central Cancer Registry, and the Information \& Statistics Division, Common Services Agency for National Health Services, Scotland. The Pennsylvania Department of Health requested a disclaimer for any responsibility on their part for any analyses, interpretations or conclusions. We thank the National Death Index and regional or national vital statistics registries for providing vital status information on patients who died and were lost to follow up.

\section{Authors' affiliations}

S Bernatsky, R Rajan, L Joseph, Y St Pierre, A Clarke, Division of Clinical Epidemiology Montreal General Hospital, Montreal, PQ, Canada
R Ramsey-Goldman, Division of Rheumatology, Northwestern University, Chicago IL, USA

R Rajan, S Lachance, D Cournoyer, Department of Oncology, Montreal General Hospital, PQ, Canada

J-F Boivin, L Joseph, Department of Epidemiology and Biostatistics, McGill University, Montreal, PQ, Canada

A Zoma, Lanarkshire Centre for Rheumatology, Hairmyres Hospital, Scotland, UK

S Manzi, University of Pittsburgh School of Medicine and GSPH,

Pittsburgh, Pennsylvania, USA

E Ginzler, SUNY-Downstate Medical Center, Brooklyn, NY, USA

M Urowitz, D Gladman, P R Fortin, Toronto Western Division of University Health Network, University of Toronto, Toronto, ON, Canada

S Edworthy, S Barr, University of Calgary, Calgary, AB, Canada

C Gordon, Department of Rheumatology, University of Birmingham,

Birmingham, UK

S-C Bae, Department of Internal Medicine, Division of Rheumatology,

The Hospital for Rheumatic Diseases, Hanyang University, Seoul, Korea

J Sibley, Department of Rheumatology, Royal University Hospital,

Saskatoon, SK, Canada

K Steinsson, Department of Rheumatology and Center for Rheumatology Research, Landspitalinn; University Hospital, Reykjavik, Iceland

O Nived, G Sturfelt, Department of Rheumatology, University Hospital, Lund, Sweden

A Clarke, Division of Clinical Immunology/Allergy, Montreal General Hospital, PQ, Canada

Ethics approval: The study was approved by the ethics review boards of all participating institutions and was conducted in accordance with the Declaration of Helsinki ethical principles.

Correspondence to: Dr S Bernatsky, 1650 Cedar Avenue, Room L10424, Montreal, Quebec H3G 1A4, Canada; sasha.bernatsky@ mail.mcgill.ca

Accepted 21 March 2005

\section{REFERENCES}

1 Bernatsky S, Boivin JF, Joseph L, Rajan R, Zoma A, Manzi S, et al. An international cohort study of cancer in systemic lupus erythematosus. Arthritis Rheum 2005;52:1481-90.

2 Mellemkjaer L, Andersen V, Linet MS, Gridley G, Hoover R, Olsen JH. NonHodgkin's lymphoma and other cancers among a cohort of patients with systemic lupus erythematosus. Arthritis Rheum 1997;40:761-8.

3 Ramsey-Goldman R, Clarke A. Double trouble: are lupus and malignancy associated? Lupus 2001;10:388-91.

4 Landis S, Murray T, Bolden S, Wingo P. Cancer statistics, 1999. CA Cancer J Clin 1999;49:8-31.

5 Boring C, Squires T, Tong T, Montgomery S. Cancer statistics, 1994. CA Cancer J Clin 1994;44:7-26.

6 Skarin AT, Dorfman DM. Non-Hodgkin's lymphomas: current classification and management. CA Cancer J Clin 1997;47:351-72.

7 Freedman A, Nadler L. NonHodgkin's lymphomas. In: Bast R, Kufe W, Pollock R, Weichselbaum R, Holland J, Frei E, eds. Cancer medicine. Canada: BC Decker Inc, 2000.

8 Baecklund E, Sundstrom C, Ekbom A, Catrina A, Biberfeld P, Feltelius N, et al. Lymphoma subtypes in patients with rheumatoid arthritis: increased proportion of diffuse large B cell lymphoma. Arthritis Rheum 2003;48: 1543-50.

9 Mariette X. Lymphomas in patients with Siögren's syndrome: review of the literature and physiopathologic hypothesis. Leuk Lymphoma 1999;33:93-9.

10 Bernatsky S, Clarke A, Boivin J, Joseph L, Rajan R, Manzi S, et al. Racial factors relating to cancer occurrence in systemic lupus (SLE) [abstract]. Arthritis Rheum 2003;48(suppl 9):S1821.

11 Wiernik PH, Wang SQ, Hu XP, Marino P, Paietta E. Age of onset evidence for anticipation in familial non-Hodgkin's lymphoma. B J Haematol 2000;108:72-9.

12 Coiffier B. Diffuse large cell lymphoma. Curr Opin Oncol 2001;13:325-34.

$13 \mathrm{Xu} Y$, Wiernik P. Systemic lupus erythematosus and B-cell hematologic neoplasm. Lupus 2001;10:841-50.

14 Jemal A, Tiwari RC, Murray T, Ghafoor A, Samuels A, Ward E, et al. Cancer statistics, 2004. CA Cancer J Clin 2004;54:8-29.

15 Benk V, Al-Herz A, Gladman D, Urowitz M, Fortin PR. Role of radiation therapy in patients with a diagnosis of both systemic lupus erythematosus and cancer. Arthritis Rheum 2005;53:67-72. 